\title{
Assessing the Efficacy of Online Lecture Modules in a Core Mechanical Engineering Undergraduate Course
}

\author{
Mohammed S. Taboun and Robert W. Brennan \\ Schulich School of Engineering, University of Calgary \\ rbrennan@ucalgary.ca
}

\begin{abstract}
In recent years, there has been a growing interest in flipped delivery of undergraduate courses. There has also been an interest in blending online learning with traditional, in-class learning. In this paper, the efficacy of a blended online course is assessed based on the second-year mechanical engineering course "Computing Tools for Engineering Design" for the Fall 2016 semester. This is an extension of a Fall 2015 study in the same course where traditional lectures were used. This study examines how the online modules are used by the students, as well as students' opinions on the video effectiveness. The results of the study painted a picture of a typical flipped delivery student: one who streams the content on a personal device/computer before the in-class session, and tends to stop/rewind the content rather than playing it continuously. Student impressions of the mode of delivery were generally positive, indicating that a combination of online lectures and in-class practice sessions support learning.
\end{abstract}

Keywords: online modules : flipped delivery

\section{INTRODUCTION}

There has been increasing interest in recent years in "flipped" delivery of undergraduate courses, where traditional lectures are substituted with active learning sessions such as project-based learning, case studies, discussion groups, etc. The most common method used to "free-up" the traditional lecture time for these active learning sessions is to move the lectures online.

Recent interest in online and hybrid (i.e., combining online and classroom instruction [10]) learning has generated extensive discussion of the benefits [8] as well as the risks [4] of these new approaches in the literature. Arguably, the most famous contribution to this area in recent years has been the "massive open online course" or MOOC [9], where students view relatively traditional lectures by a prestigious professor through an online forum (a good example of this approach is Harvard's introductory computer science course "CS 50").

Although online delivery has generated much interest in higher education, institutions struggle with its implementation [2]. As well, it is not clear that this single technological solution (online lectures) is warranted: particularly, in disciplines such as engineering where inperson activities such as project-based learning and laboratories are necessary. As a result, there has been interest in hybrid learning techniques such as "flipped" learning [1] where online lectures are used to open-up time for more meaningful activities in the in-person sessions (e.g., discussions, case studies, projects, problem solving sessions, etc.). Arguably, the flipped approach does not require an online component - as Cussler [6] notes, "flipped" has existed for many years in the form of out of class preparation (e.g., reading a play prior to class) - but recording lectures for students prior to class, does provide a convenient way to free up the in-class time for other activities.

The verdict is still out on the benefits of online learning. However, there does appear to be growing consensus that online learning in isolation can be problematic with respect to student completion and student assessment [5]; but when online learning is combined with face-to-face activities, students can learn even more than in traditional or purely online approaches $[10,11]$.

In this paper, we assess the efficacy of online lectures in a "flipped" offering of the second year, core Mechanical Engineering course "Computing Tools for Engineering Design". This is an extension of a Fall 2015 study in the same course where both online and "traditional" lectures were used [3].

The objective of this research is to gauge how the online video lectures are used by students as well as their opinions the online video lectures effectiveness. The research question addressed by this research is:

$$
\begin{aligned}
& \text { Are online video lectures an effective means of } \\
& \text { delivering lecture content in an undergraduate } \\
& \text { computing course? }
\end{aligned}
$$

In the Fall 2016 offering of "Computing Tools for Engineering Design", all lectures were delivered using an online video format. Students were asked to complete a survey on the online video lectures over the course of the term. The purpose of the survey was two-fold: (1) to gauge 
how students used the online video modules, and (2) to obtain student opinion of the modules efficacy in the context of their learning in the course.

In the next section, we describe the methods used for this research study. We follow this, with a summary of the results of the survey in Section 3 and our conclusions in Section 4 .

\section{METHODS}

\subsection{The Class}

Following research ethics board approval, this study was conducted in the Fall 2016 term in the Schulich School of Engineering second year course, Mechanical Engineering 337 "Computing Tools for Engineering Design". This course is a continuation of the first-year computing course, Engineering 233 "Computing for Engineers", where students are introduced to computer systems and programming in a high-level language. The goal of this second-year course is to provide students with experience in applying high-level software (in this case, MATLAB [7]) to the solution of mechanical engineering design problems.

Since its introduction into the B.Sc. in Mechanical Engineering curriculum, "Computing Tools for Engineering Design" has been taught in the traditional fashion of 3 hours of lectures per week, with a single 3hour laboratory every week. Presently, the course is offered each Fall term (September to December) to approximately 200 second-year students, who attend a single lecture section which is then divided into six laboratory cohorts of approximately 33 students.
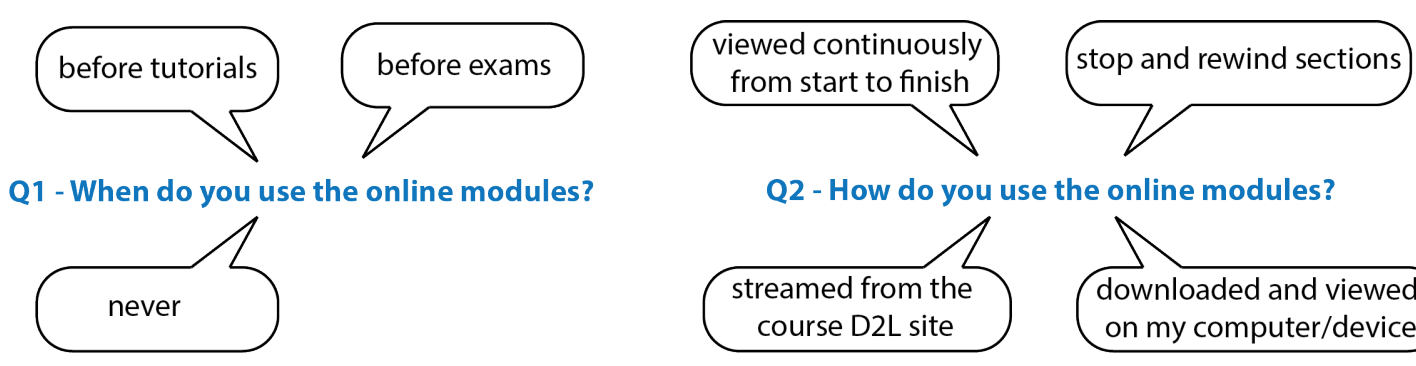
designed the course to have a blended, flipped learning approach. Lectures on the software covered in the course were delivered online in a video format, along with one weekly problem solving session. Videos were posted online for the students to view at their own pace, and they were provided before the weekly in-class portion. During the in-class portion, students had the opportunity to ask questions that they normally don't have in traditional online courses. In cases where there were no questions, or the questions did not fill the time slot, sample problems were completed on the board as a group.

\subsection{The Classroom Survey}

As noted in Section 1, the purpose of the survey was to determine (1) how students used the online modules, and (2) how the online modules contributed to student learning. For the first objective, three questions - framed as "when", "how", and "where" - were used. For each question, students were asked to select one or more responses; students were also given the option to select "other" and specify the approach used. The first three questions are shown in Figure 1.

In order to obtain feedback on student impressions of the online modules, students were asked to indicate their degree of agreement with each of the following statements. As scale of 0 (disagree) to 100 (agree) was used for each question.

Q4 - My learning is the same with online lectures as with in class lectures.

Q5 - I could pass the course without teacher assistance.

Q6 - I need in-class activities to learn.
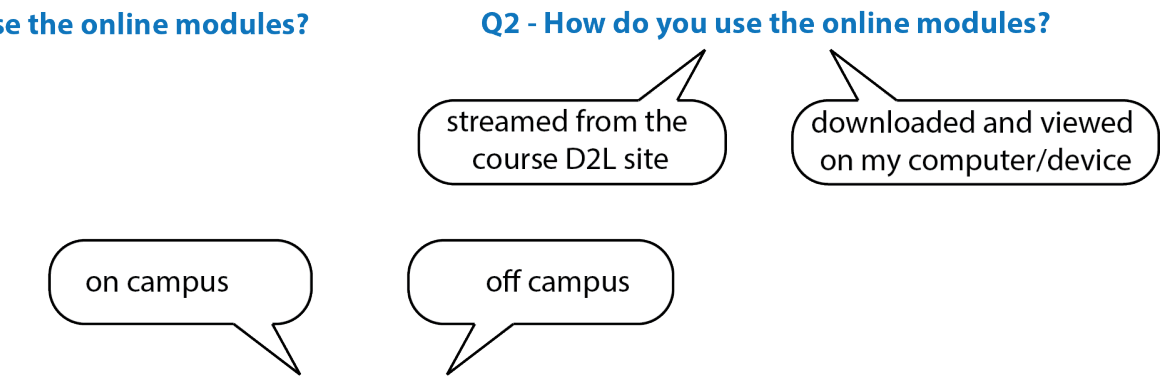

Q3 - Where do you typically view the online modules?
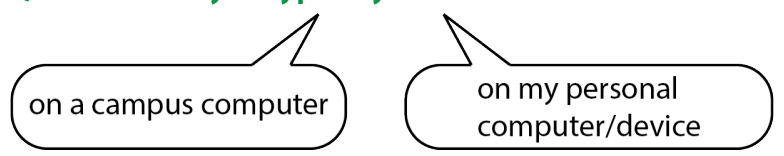

Fig. 1. Survey questions relating to online module usage.
CEEA17; Paper 031

University of Toronto; June 4-7, 2017 


\section{RESULTS AND DISCUSSION}

In this section, we summarize the results of the surveys our second year computing tools for engineering design students that were run in Fall 2016 (response rate $=25 \%$ ). We begin with a summary of the questions related to the online module usage (Q1-Q3), then present the results of the three questions on student impressions of the online modules (Q4-Q6). The section concludes with a summary of our experience and reflections on the development of the online modules.

\subsection{Online Module Usage}

As noted in the previous section, the three "usage" questions relate to when, how, and where the online modules were used by students. Beginning with the first question, the majority of students ( $85 \%$ ) view the modules before tutorials. In this case, given that the course is run in a flipped fashion, the lecture sections are used as problem solving sessions that are interpreted as "tutorials" by the students.

Figure 2 combines the two "how" questions related to usage: how the modules are viewed (represented by the size of the rectangles), and how the modules are accessed (represented by the colours of the rectangles).
As shown in this figure, the response is almost equally split between "continuous" viewing and "stop/rewind" viewing, with majority of students streaming to access the content. Students who indicated that they use "other" approaches typically downloaded the video content and watched it at high speed ( $1.5 \mathrm{x}$ or $2 \mathrm{x})$; as well, some students indicated that they used other online resources (e.g., MATLAB videos) or did not use any online resources.

Figure 3 combines the two "where" questions relating to usage: i.e., where was the content accessed (colour of rectangles) and on what device (size of rectangles). The majority of students access the modules off-campus, on their personal device.

The purpose of the three questions relating to student impressions of the online content, was to gauge how students viewed the online modules and flipped mode of delivery in the context of their learning. In order to simplify the presentation of the results, we classified the agreement data into four categories:

$$
\begin{array}{rc}
\text { "disagree" } & 0<\text { agreement level } \leq 25 \\
\text { "moderately disagree" } & 25<\text { agreement level } \leq 50 \\
\text { "moderately agree" } & 50<\text { agreement level } \leq 75 \\
\text { "agree" } & 75<\text { agreement level } \leq 100
\end{array}
$$


How (Accessed)

- downloaded

- other

- streamed

II streamed and downloaded

Fig. 2. How the online modules are used by students. 


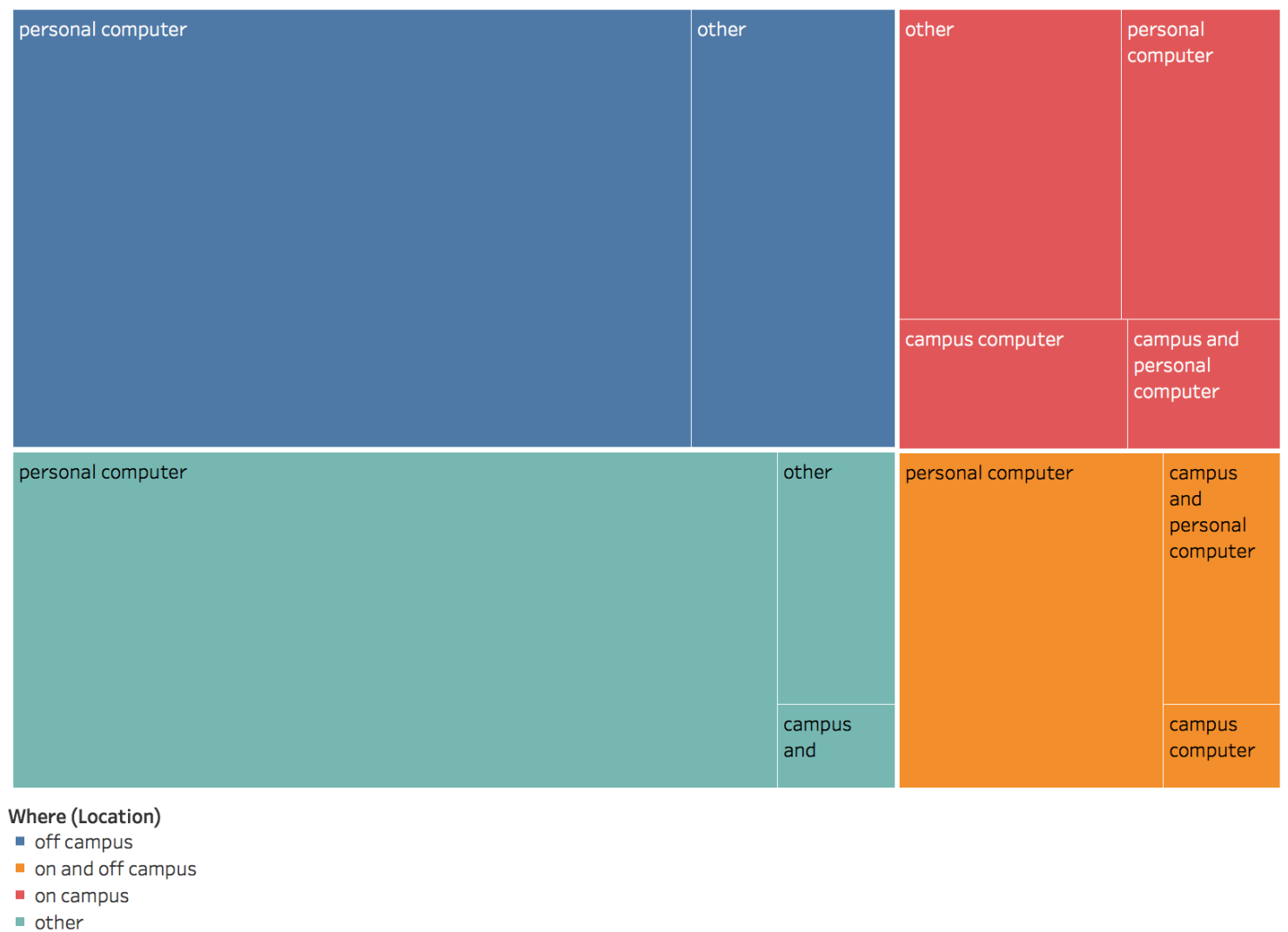

Fig. 3. Where the online modules are used by students.

The results for the first two questions, which related to student learning in the absence of online lectures (Q4) and teacher assistance (Q5), are summarized in Figure 4.

In this figure, the column locations correspond to Q4, while the colours correspond to Q5. For example, the most common combination of responses to Q4 and Q5 is represented by the blue circle in the left column: 15 students indicated that they agreed with both Q4 and Q5: i.e., students agreed that their learning is the same with online lectures as with in class lectures, and that they could pass without teacher assistance.

It seems logical that students who see no difference between online and in-class lectures, would agree that they could pass the course without teacher assistance. Following this line of reasoning, one would expect to also see the opposite effect: i.e., students who disagree with Q4 and Q5. Although this is the largest group in the right column (7 students), a similar number of students (6 students) agree with Q4, while disagreeing with Q5. These results are likely confounded by students' impressions of "teacher assistance". More specifically, the flipped mode of instruction in the course provides opportunities for teacher assistance as well as online lectures.

This is supported by the results of Q6, shown in Figure 5: i.e., the majority of students agree that in-class activities are needed to support learning.

\section{CONCLUSIONS}

The results of the study help to paint a picture of the typical student in this flipped learning environment: i.e., a student who streams the online modules, on their personal device, off-campus, before the tutorial sessions; and tends to stop and rewind the content rather than playing it continuously. Although this result is not surprising, it does speak to the convenience of online modules for students. More specifically, given the opportunity, students access lecture content in non-traditional ways (at home, played back) and when it is needed (prior to in-class practice sessions).

The student impressions of the online content should be viewed in the context of the course content: i.e., a second year computing course. Given the nature of computing, felt that a flipped mode of online lectures and extra practice sessions (traditional lecture time) would best support learning. The student impressions results appear to support this. For example, although the Figure 4 results are not significant, they are skewed toward agreement that the teaching resources support independent learning. The Figure 5 results are clearer: showing that in-class activities are needed to learn the material. By moving the lectures online, we were able to provide additional time for these in-class activities. 


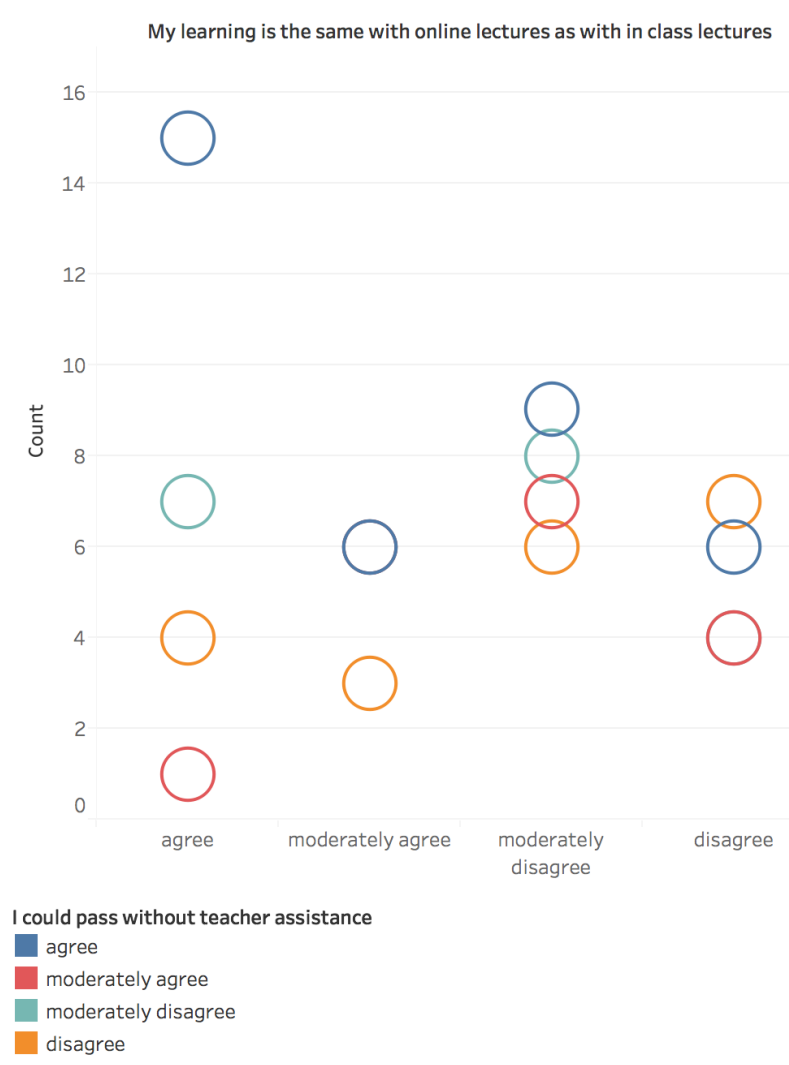

Fig. 4. Student impressions: Q4 and Q5.

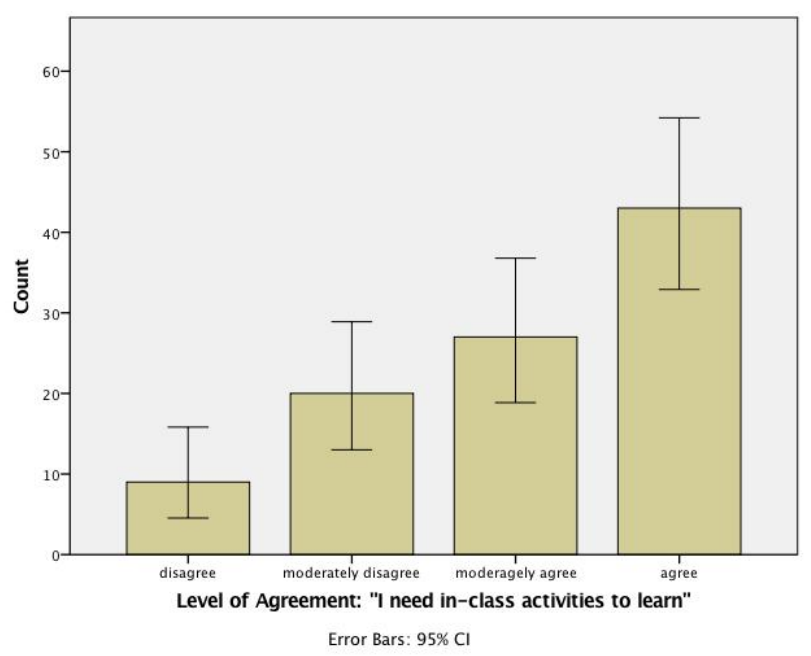

Fig. 5. Student impressions: in-class activities.

The next step in this research is to compare the student usage and impressions results with student outcomes. For example, it would be interesting to determine if different modes of usage impact student learning, and if students' opinions of their learning are consistent with their outcomes. Comparing this flipped mode of delivery with a control group (i.e., traditional, lecture-based delivery) would strengthen this work. Unfortunately, this is not always possible given timetabling and course assignment constraints; however, we will pursue this design in future studies.

\section{Acknowledgements}

The authors wish to thank the Natural Sciences and Engineering Research Council, Spartan Controls, the Suncor Energy Foundation, and the Schulich School of Engineering for their generous support of this research. This research study was approved by the University of Calgary Conjoint Faculties Research Ethics Board (Ethics ID REB16-1821).

\section{References}

[1] A.M. Al-Zahrani, "From passive to active: The impact of the flipped classroom through social learning platforms on higher education students' creative thinking", British Journal of Educational Technology, vol. 46, no. 6, pp. 1133-1148, 2015.

[2] A.W. Bates, Managing technological change. San Francisco, CA: Jossey-Bass, 2010.

[3] R.W. Brennan, L. Vathje, and M. Eggermont, “Assessing the efficacy of supplemental online lecture modules in a core mechanical engineering undergraduate course", Proceedings of the 123rd American Society for Engineering Education Conference and Exposition, New Orleans, June 26-29, 2016.

[4] N. Carr, The Shallows: What the Internet is Doing to our Brains. New York, NY: Norton \& Company, 2011.

[5] J. Dutton, M. Dutton, and J. Perry, "Do online students perform as well as lecture students?", Journal of Engineering Education, January 2011.

[6] E.L. Cussler, "The future of the lecture", American Institute of Chemical Engineers Journal, vol. 61, no. 5, 2015.

[7] A. Gilat, MATLAB: An Introduction with Applications, John Wiley \& Sons, 2011.

[8] N. Heller, "Laptop U: Has the future of college moved online?”, The New Yorker, May 20, 2013.

[9] L. Pappano, "The year of the MOOC", The New York Times, November 2, 2012.

[10] P.S. Peercy and S.M. Cramer, "Redefining quality in engineering education through hybrid instruction", Journal of Engineering Education, vol. 100, no. 4, pp. 625-629, 2011 .

[11] U.S. Department of Education, Office of Planning, Evaluation, and Policy Development. Evaluation of evidence-based practices in online learning: A meta-analysis and review of online learning studies. Washington, DC: U.S. Department of Education, Office of Planning, Evaluation and Policy Development, 2010. 